\title{
Numerical Study of Pipe Pile Behaviour in Clays Considering Inner and Outer Shaft Frictions
}

\author{
Kicheol Lee, Byunghyun Choi, Jongho Park, Dongwook Kim \\ Incehon National University \\ 119 Academy-ro, Yeonsu-gu, Incheon 22012, Republic of Korea \\ wlq4619@inu.ac.kr; qudgus555@inu.ac.kr; rdvagabond@gmail.com; wookdong2@gmail.com
}

\begin{abstract}
Axial resistance of open-ended steel pipe pile is influenced by the external frictional resistance generated between the outer pile surface and its surrounding soils and the internal frictional resistance generated between the pile inner surface and plugged soils. For the assessment of axial pile resistance including its ultimate load, characteristics of both external and internal shaft frictional resistances should be examined. However, limited previous research was available. In this study, the effects of frictional resistance characteristics on the long-term ultimate loads were analysed through numerical analysis. As results, the long-term pile ultimate loads were numerically quantified. It was found that the effect of the outside friction coefficient on pile resistance was more significant compared with inside friction coefficient's contribution on pile resistance.
\end{abstract}

Keywords: Open-Ended Steel Pipe Pile, Ultimate Load, Surface Interface Friction Coefficient, Numerical Analysis.

\section{Introduction}

In the case of open-ended steel pipe piles (OESPP), frictional forces are acting on both outer pile shaft surface and inner pile shaft surface. The external frictional resistance on outer pile surface is mobilized between pile surface and the pile's surrounding ground, while the internal frictional resistance on inner pile surface is exerted between pile surface and plugged soils resulted from pile installation process[1]. Examination of these external and internal frictional resistance characteristics is important to evaluate their separate effects on pile ultimate load and behaviour. Limited literature on the quantification of these effects is available; therefore, in the study, the changes of long-term ultimate load of OESPP in clays for different combinations of external and internal frictional resistance characteristics were analysed based on numerical analysis results. Numerical program of ABAQUS/CAE [2] was used for the numerical analysis. The important frictional characteristic of interface friction coefficients of inner and outer frictions were varied in combinations from 0.2 to 1.0 (in increments of 0.2 ), respectively. For different combinations of friction coefficients $\left(\mathrm{c}_{\text {in }}\right.$ and $\mathrm{c}_{\text {out }}$ ), long-term ultimate pile loads were analysed in details.

\section{Numerical Analysis}

\subsection{Modelling}

Long-term pile ultimate loads for different combinations of internal and external friction resistance characteristics of OPSPP were analyzed using ABAQUS/CAE [2], which is three-dimensional finite element program. The material properties of the clay foundation and the OESPP used in numerical analysis are summarized in Table 1. For numerical modelling of clay foundation, the outer boundary of clay foundation is assumed to be a large cylindrical shape with a diameter of $25 \mathrm{~m}$ and a height of $30 \mathrm{~m}$. The embedment depth, total length, diameter, and thickness of OESPP are assumed to be $25 \mathrm{~m}, 30 \mathrm{~m}, 0.5 \mathrm{~m}$, and $0.012 \mathrm{~m}$, respectively (Fig. 1). To ensure that the outer boundary of clay foundation is sufficient not to have boundary issue in analyses, sufficient ratio (50) of clay foundation outer boundary diameter $(25 \mathrm{~m})$ to pile diameter $(0.5 \mathrm{~m})$ is assumed.

\subsection{Frictional Interaction Characteristics of Inner and Outer Pile Surfaces}

The frictional interaction characteristics of clay-steel surface interface are summarized in Table 2. In ABAQUS / CAE, the master surface and the slave surface must be set when setting the interface frictional surfaces. The interface between 
clay and steel surface on clay foundation is set as the master surface because typically the master surface is set for larger model (clay foundation model is far larger than pile model); thus, the interface on pile is set as slave surface.

Table 1: Material properties used in the analysis.

\begin{tabular}{|c|c|c|}
\hline Property & Open-ended Steel pipe pile (OESPP) & Soft clay \\
\hline Model & Elastic & Mohr-Coulomb \\
\hline Young's modulus, E $(\mathrm{MPa})$ & 200,600 & 3 \\
\hline Cohesion, c $(\mathrm{kPa})$ & - & 0.3 \\
\hline Poisson's ratio, $v$ & 0.3 & 20 \\
\hline Friction angle, $\varnothing\left(^{\circ}\right)$ & - & 18 \\
\hline Unit weight, $\mathrm{Y}\left(\mathrm{kN} / \mathrm{m}^{3}\right)$ & 76.82 & 0.65 \\
\hline $\begin{array}{c}\text { Lateral coefficient of earth pressure at } \\
\text { rest, } \mathrm{K}_{0}\end{array}$ & 1 & \\
\hline
\end{tabular}

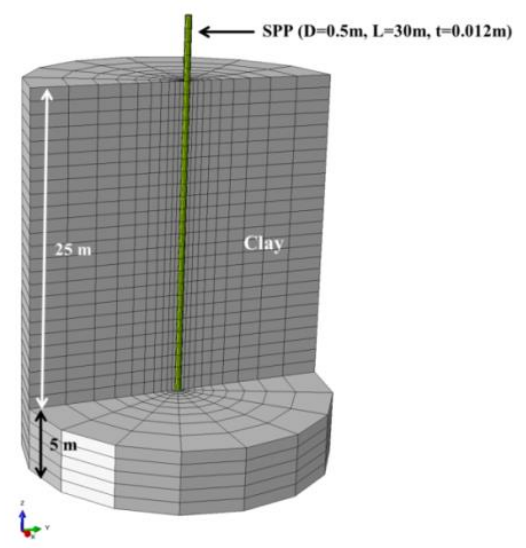

Fig. 1: OESPP and clay foundation modelling used in the analysis.

The frictional interaction condition was assumed to be combination of "hard contact" and "tangential behaviour." The "hard contact" covers typical condition of interface between two different materials and the "tangential behaviour" specifies frictional properties such as friction coefficient of interface surfaces. Typical friction coefficient between soil and steel pile shaft ranges from 0.2 to 1.0 depending on roughness of pile surface and particle size distribution. The analysis was carried out by changing the coefficients of friction of inner and outer pile shaft surface (interface frictional coefficient between soft clay and OESPP). The friction force is applied when the friction surface between the contact bodies is set. When the magnitude of the shear stress reaches the threshold, the body slips, otherwise it does not move. This friction has a disadvantage that it is difficult to obtain a solution because the nonlinear effect is very large. However, in ABAQUS/CAE, the analysis equation of friction value is made as unsymmetrical, and when the friction coefficient is larger than 0.2 , the 'unsymmetrical solver' works. 
Table 2: Interaction characteristics used in numerical analysis.

\begin{tabular}{|c|c|c|c|}
\hline Master surface & Slave surface & Normal behaviour & Tangential behaviour \\
\hline Soft clay surface on inner pile shaft & Inner shaft surface of pile & Hard contact & Penalty-friction coefficient $=0.2 \sim 1.0$ \\
\hline Soft clay surface on outer pile shaft & Outer shaft surface of pile & Hard contact & Penalty-friction coefficient $=0.2 \sim 1.0$ \\
\hline $\begin{array}{c}\text { Soft clay surface in contact with } \\
\text { pile bottom's cross section }\end{array}$ & Pile bottom's cross section & Hard contact & - \\
\hline
\end{tabular}

\subsection{Analysis of Load-Settlement Curves and Ultimate Loads of OESPP}

In order to analyze the ultimate load of the OESPP, the maximum pile head displacement (settlement) of $0.1 \mathrm{~m}$ was controlled and the reaction force was analyzed for each increment of settlement. The analysis is repeated by varying combination of friction coefficients of the inner and outer interface surfaces, and the corresponding load-settlement curves were derived. From each load-settlement relationship, pile ultimate load was determined through Davisson's Criterion ([3] and [4]).

\section{Results of Numerical Analysis}

\subsection{Load-Settlement Curves of OESPP}

Figure 2(a) shows the pile load-settlement curves varying outer friction coefficient $c_{\text {out }}$ from 0.2 to 1.0 for given inner friction coefficient $c_{i n}$ of 0.2 . As a result of the analysis, the $c_{\text {in }}$ was found to have little effect on axial behaviour of OESPP. Significant change of axial OESPP behaviour was found for $\mathrm{c}_{\text {out }}$ increase from 0.2 to 0.6 ; however, little change was observed for $\mathrm{c}_{\mathrm{out}}$ exceeding 0.6. Figure 2(b) shows the pile load-settlement curves varying $\mathrm{c}_{\text {in }}$ from 0.2 to 1.0 under fixed $\mathrm{c}_{\text {out }}$ of 0.2 . Overall, insignificant change of pile load-settlement curve was shown under pile settlement less than $50 \mathrm{~mm}$ (corresponding to $10 \%$ of pile diameter, which is a significant settlement). From the comparison of Figure 2(a) and Figure 2(b), the effect of outer friction coefficient on axial pile behaviour was much significant than that of inner friction coefficient.

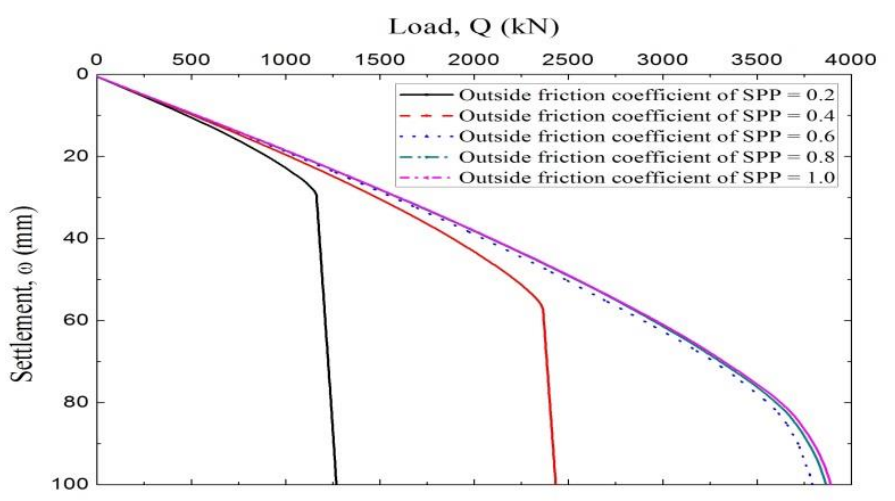

(a)

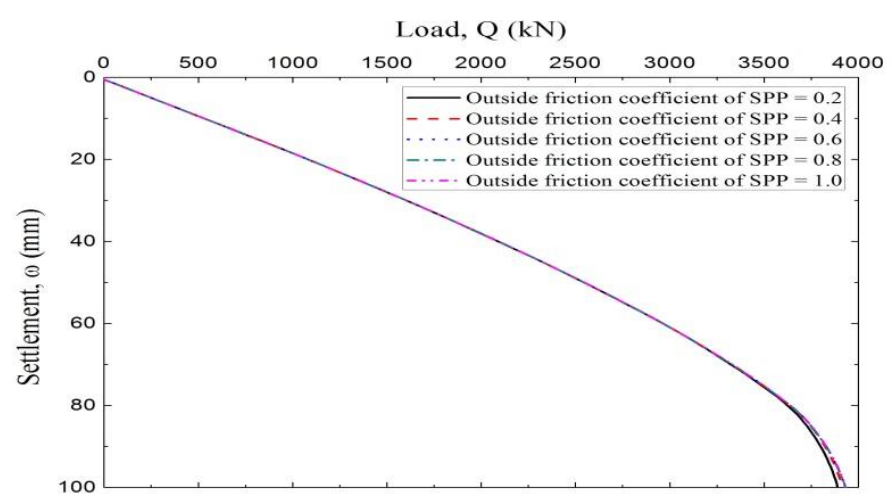

(b)

Fig. 2: Pile load-settlement curves; (a) outer friction coefficient varied from 0.2 to 1.0 for the given inner friction coefficient of 0.2 ; (b) inner friction coefficients varied from 0.2 to 1.0 for the given outer friction coefficient of 0.2 .

The determined pile ultimate loads using Davisson's criterion from Figure 2 for different combinations of inner and outer friction coefficients are summarized Table 3. The minimum pile ultimate load $(1,197 \mathrm{kN})$ is achieved when both inner and outer friction coefficients $\left(\mathrm{c}_{\text {in }}\right.$ and $\left.\mathrm{c}_{\mathrm{out}}\right)$ are the minimum $(0.2)$. The maximum pile ultimate load $(3,179 \mathrm{kN})$ was obtained when outside and $c_{\text {out }}$ was 1.0 and $c_{\text {in }}$ exceeds 0.4 . The ratio of the maximum-to-minimum calculated ultimate load is about 2.65, which is a large value. However, it is noteworthy to know that pile ultimate loads (underlined values in Table 3 ) somewhat converge to a certain values for $c_{\text {out }}$ exceeding 0.6 regardless of $c_{\text {in }}$ value. The results in Table 3 are alternatively shown in Figure 3. 
Table 3: Ultimate loads with inside and outside friction coefficient using Davisson's criterion.

\begin{tabular}{|c|c|c|c|c|c|c|}
\hline \multirow{7}{*}{$\begin{array}{c}\text { Ultimate } \\
\text { load } \\
(\mathrm{kN})\end{array}$} & \multirow{2}{*}{ Outer friction coefficient (cout) } & \multicolumn{5}{|c|}{ Inner friction coefficient $\left(c_{\text {in }}\right)$} \\
\hline & & 0.2 & 0.4 & 0.6 & 0.7 & 1.0 \\
\hline & 0.2 & 1,197 & 1,225 & 1,251 & 1,254 & 1,254 \\
\hline & 0.4 & 2,370 & 2,398 & 2,422 & 2,424 & 2,425 \\
\hline & 0.6 & 3,096 & 3,117 & 3,125 & 3,122 & 3,126 \\
\hline & 0.8 & 3,153 & 3,165 & 3,165 & 3,167 & 3,168 \\
\hline & 1.0 & 3,177 & 3,179 & 3,179 & 3,179 & 3,179 \\
\hline
\end{tabular}

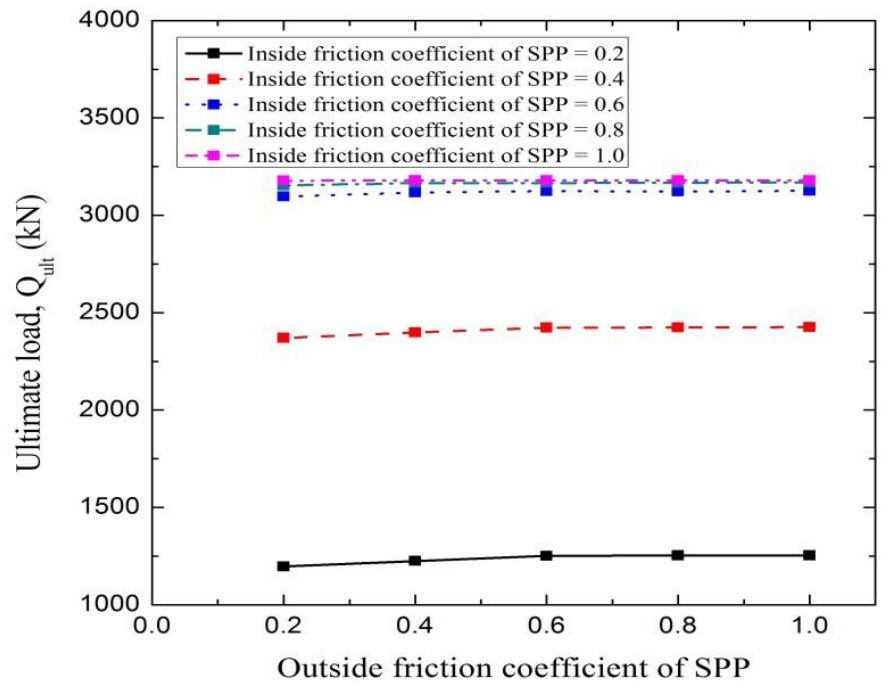

(a)

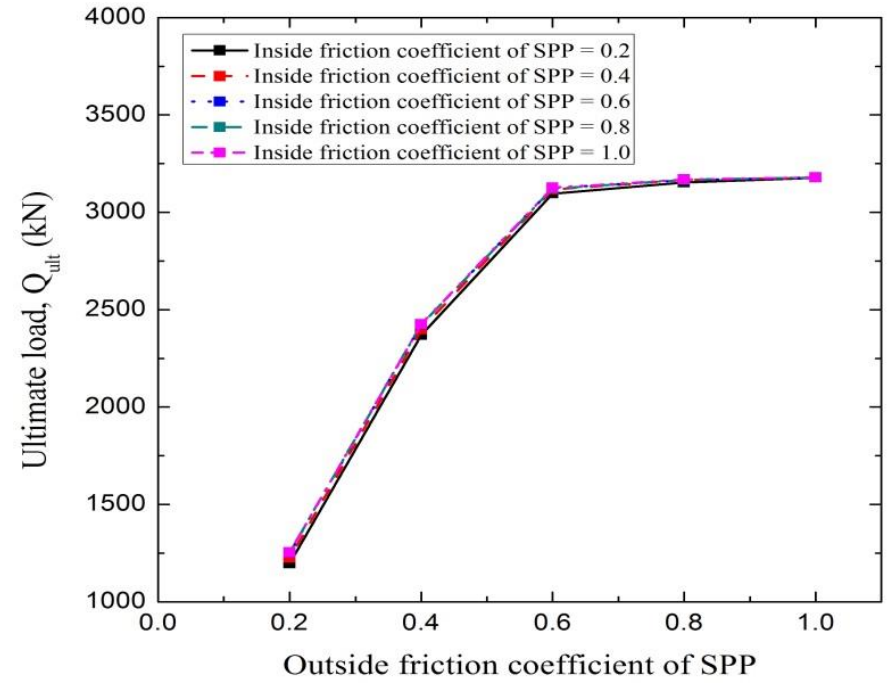

(b)

Fig. 3: Ultimate load based on the Davisson's criterion: (a) effect of inner friction coefficient on ultimate load and (b) effect of outer friction coefficient on ultimate load.

\section{Conclusion}

The purpose of this study is to investigate the ultimate load changes varying combination of internal and external friction resistance characteristics (inner and outer friction coefficients) of the steel pipe pile. The ABAQUS / CAE, a general-purpose program, was used for the numerical analysis program, and the friction coefficients of interface surfaces between the steel pipe pile and the clay foundation were varied within a range of 0.2 through 1.0. As a result, the inner friction coefficient $\left(c_{\text {in }}\right)$ did not have a significant effect on the load-settlement curve of pile; however, the outer friction coefficient $\left(\mathrm{c}_{\mathrm{out}}\right)$ significantly influences axial pile behaviour. It was interesting that the significant effect of outer friction coefficient on pile behaviour diminishes for outside friction coefficient $\left(\mathrm{c}_{\text {out }}\right)$ exceeding 0.6. In order to improve the reliability of the analysis results, it is necessary to perform a comparative analysis from laboratory and field tests.

\section{Acknowledgements}

This work was supported by the National Research Foundation of Korea (NRF) grant funded by the Korea government (MSIP) (No. 2015R1C1A1A02037490).

\section{References}

[1] H. Matsumiya, Y. Ishihama, and S. Taenaka, "A study on the bearing capacity of steel pipe piles with tapered tips,” Japanese Geotechnical Society Special Publication, vol.1, no.6, pp. 47-52, 2015.

[2] SIMULIA, "6.14 Documentation Collections," ABAQUS/CAE User's Manual, 2014. 
[3] M. T. Davisson, "Highway Capacity Piles," Proc. Lectures series on innovations in foundation construction, ASCE, Illinois Section, Chicago, 1972.

[4] M. T. Davisson, "Piles Load Capacity," Proc. ASCE Conf. Design Construction and Performance of Deep Foundation, ASCE, University of California, Berkeley, 1975. 